\title{
CHAKINAN
}

Número 11 / AGOSTO, 2020 (82-96)

Mary Beatriz Jadán Veriñez maryjadan@hotmail.com

Investigadora Independiente.

Guayaquil, Ecuador

ORCID:

http://orcid.org/0000-0003-4232-5594

\section{LOS MONTÍCULOS COMO INDICADORES ARQUEOLÓGICOS DE LA SACRALIDAD DE LOS SEÑORÍOS CAÑARIS}

THEMOUNTAINSASARCHAEOLOGICAL INDICATORS OF THE SACRALITY OF LOS CANARIS

DOI:

https://doi.org/10.37135/chk.002.11.06

Artículo de Revisión

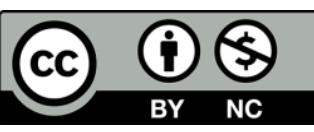




\section{LOS MONTÍCULOS COMO INDICADORES ARQUEOLÓGICOS DE LA SACRALIDAD DE LOS SEÑORIOS CAÑARIS}

\author{
THE MOUNTAINSAS \\ ARCHAEOLOGICAL \\ INDICATORSOF THE \\ SACRALITY OFLOS \\ CAÑARIS
}

\section{Resumen}

Aunque la etnohistoria presenta abundante información respecto a los pueblos locales, la arqueología no ha logrado definir suficientemente en su materialidad a la sociedad cañari. Al abordar esta investigación se proyecta contribuir al estudio de los montículos de tierra o plataformas ubicadas en las cumbres de las montañas y los cerros coronados con piedras emplazados en la región centro sur y sur andina del Ecuador. Mediante el rastreo bibliográfico y utilizando los métodos analítico, sintético y empírico, se ubican estos contextos arqueológicos y se les compara con la información etnohistórica de los pueblos locales. Se analizan, además, los contextos arqueológicos encontrados en los sitios Cerro Puñay y Guiñayzhu. Como resultado, se detecta una recurrencia de estos vestigios en la región adscrita a los cañaris prehispánicos y se considera que todas estas evidencias están relacionadas con los rituales de los cerros, por lo que resulta importante su conocimiento para el fortalecimiento de la cultura e identidad andina.

Palabras clave: Montañas, montículos o plataformas, ritual de los cañaris, cerro Puñay

\section{Abstract}

Even though ethnohistory has produced abundant information regarding local peoples, archeology has not managed to sufficiently define the materiality of Cañari society yet. Therefore, this research aims to contribute to the study of mounds of earth or platforms located on the summits of the hills, and hills crowned with stones that are situated in the central south and south Andean region of Ecuador from the bibliographic tracking, and using analytical, synthetic and empirical methods. These archaeological contexts are studied and compared with the local-people ethnohistorical information. In addition, the archaeological contexts found at Cerro Puñay and Guiñayzhu sites are also studied. It is assumed that there is a recurrence of these vestiges in the region attached to the prehispanic cañaris. It is believed that all these evidences are related to the rituality of the hills and that their knowledge is important for the strengthening of the Andean culture and identity.

Keywords: Hill, mounds or platforms, ritual of the cañaris, cerro Puñay 


\section{INTRODUCCIÓN}

La información de los cacicazgos cañaris, basada en documentos etnohistóricos es copiosa, pero la arqueología no ha logrado todavía definir indicadores materiales suficientes (a excepción de los pocos estudios de su cerámica), probablemente porque muchos sitios con la conquista inka fueron reconstruidos y se cubrió o se destruyó mucha información de los pueblos locales; a lo que se añade los escasos estudios arqueológicos realizados.

Esta sociedad ocupó un amplio territorio en el área sur andina del Ecuador, desde el 500 d. C. hasta el 1460 d. C. Al norte llegaron hasta el nudo del Azuay, al sur se ha reportado sitios en la cordillera de Chilla, al este llegaron hasta el valle del Upano y el curso inferior del Zamora (Salazar 2004:53) y de acuerdo con González (1878:3), hacia el oeste alcanzaron las costas del Pacífico.

Según la información etnohistórica, se organizaron mediante jefaturas locales, grandes o menores, no estaban confederados, se mantenían independientes, pero en situaciones especiales (enfrenamientos bélicos, de interés económico o religioso), mantenían coaliciones.

Los cañaris, además, dominaron el relieve andino, utilizaron las cimas de las montañas y las laderas; manejaron los accidentes geográficos como demarcadores de sus territorios (De Salinas 1992; Cieza de León 2005; Gaviria 1992; Arias 1992).

Asimismo, la arqueología reporta cotas arriba de $\operatorname{los} 2500 \mathrm{~m}$ de altura, tanto en las montañas que envuelven la cuenca del río Cañar, como los sitios arqueológicos de la cuenca del río Jubones. Desde las partes altas de las colinas, los cañaris se apropiaron de los valles interandinos con asentamientos de tipo disperso, muchos de estos sitios fueron utilizados como espacios ceremoniales y de culto; aunque al mismo tiempo eran lugares de control político y económico.

Por otra parte, existen ciertas evidencias arqueológicas encontradas en la cumbre de los cerros y que probablemente estén relacionadas con la ritualidad de los señoríos cañaris.

Entre los investigadores que describen estas manifestaciones se encuentran: Vernau y Rivet (1912); González (1956); Odaira (1998); Idrovo (2006); Galarza, Almeida y Guzmán (2014) y Jadán (2015, 2017).

Considerando estos precedentes, este estudio se enfocará en contextos como cerros coronados de piedras, plataformas de tierra y cerros de contorno piramidal, que aparecen citados en la etnohistoria y confrontará la información, con los aislados datos arqueológicos que afloran en los documentos publicados e informes arqueológicos arriba citados y también, con la información encontrada en los sitios Guiñayzhu y Cerro Puñay (Jadán 2017; 2018).

En esta secuencia, el objetivo de este estudio se relaciona con rastrear las evidencias materiales que permitan conocer su recurrencia en los sitios arqueológicos de la región centro sur y sur andina del Ecuador y aproximarnos a un conocimiento de la ritualidad de los cerros venerados por los cañaris; conocimiento muy importante para el fortalecimiento de la cultura e identidad andinas.

\section{METODOLOGÍA}

Este artículo de revisión y reflexión se adecua a la fase exploratoria de un diseño de investigación del tipo explicativo, como lo han planteado Tarragó y Nuñez (1972). Este tipo de diseño permite indagar las relaciones que existen entre fenómenos con el fin de posibilitar respuestas sobre el problema planteado. Nuestro objeto es el estudio de la materialidad que presenta la sociedad cañari prehispánica, como respuesta a ciertos fenómenos o necesidades que como sociedad debe resolver. 
Específicamente, nos ocuparemos de las relaciones existentes entre los montículos de tierra construidos en la cúspide de los cerros, los cerros señalados y la ritualidad. Al ser una fase exploratoria, el primer objetivo es la búsqueda de las evidencias. En este sentido, se recurre a la observación y análisis de los datos provenientes de fuentes etnohistóricas, a la información publicada en diferentes medios, tales como libros, revistas e informes arqueológicos y al registro arqueológico de campo.

Se utiliza los métodos analítico, sintético y empírico. El método analítico y sintético facilita la revisión ordenada mediante la elaboración de fichas técnicas para la descripción de las peculiaridades de cada sitio citado en las fuentes etnohistóricas; especialmente se utilizó la obra de Pilar Ponce Leiva titulada "Relaciones históricos geográficas de la Audiencia de Quito Siglo XVIXIX" (1992) tomo I, que contiene los comentarios de Martin de Gaviria (1992); Juan de Salinas Loyola (1992); Pedro Arias Dávila (1992), entre otros.

Las publicaciones de Duviols Pierre (1967), la primera titulada: "Un inédit de Cristóbal de Albornoz: La instrucción para descubrir todas las guacas del Pirú y sus camayos y haziendas" y la obra llamada: "La destrucción de las religiones andinas" (1977). Asimismo se analizaron otras fuentes primarias como: Garcilaso de la Vega (1609); Cieza de León (2005) y Pablo Arriaga (1968).

Además, se examinó y sintetizó la información encontrada en las obras del historiador Federico González Suárez $(1878,1969)$; las investigaciones de Verneau y Rivet en el documento "Etnografía antigua del Ecuador" (2009). No podemos dejar de mencionar el estudio de Segundo Moreno Yánez (2007), titulado: "Ofrenda sacrificial al Guagualzuma"; los trabajos de Celiano González (1956); Odaira (1998); Idrovo (2006); Galarza et. al (2014) y Checa (2014). Al mismo tiempo, se revisaron publicaciones e informes arqueológicos referentes al área sur andina que se encuentran en el Instituto Nacional de Patrimonio Cultural del Ecuador.
A partir de este fichaje de información se definieron los rasgos relacionados con probables adoratorios. Se seleccionaron por el principio de recurrencia cuatro indicadores: la construcción o modificación de la cúspide de los cerros, la forma circular de las construcciones, los elementos de construcción utilizados de los montículos que son la tierra y piedra y la disposición del corte de la piedra rústica en el lado eterno. La correlación entre el dato arqueológico y el dato etnohistórico, respecto a los cerros señalados, fue la presencia de piedra en la cúspide de cerros definidos como sitios arqueológicos.

Por otra parte, el trabajo empírico y teórico fue realizado a través de la observación, descripción, medición y análisis sistemático de los contextos arqueológicos encontrados en los sitios Cerro Puñay (Jadán 2017) y Guiñayzhu (Jadán 2018), donde además se localizó cerámica local. De esta forma, todas estas evidencias fueron confrontadas con la información confinada en las diferentes fuentes ya mencionadas.

La muestra analizada se encuentra referida en la tabla 1 y corresponde a treinta y un sitios arqueológicos; ocho de los cuales son citados en documentos etnohistóricos, veintiún sitios son referidos en informes arqueológicos o documentos publicados y dos sitios fueron investigados por la autora (figura 1). 
Fuente: Elaboración de la autora con la colaboración de Seearth Consulting Group

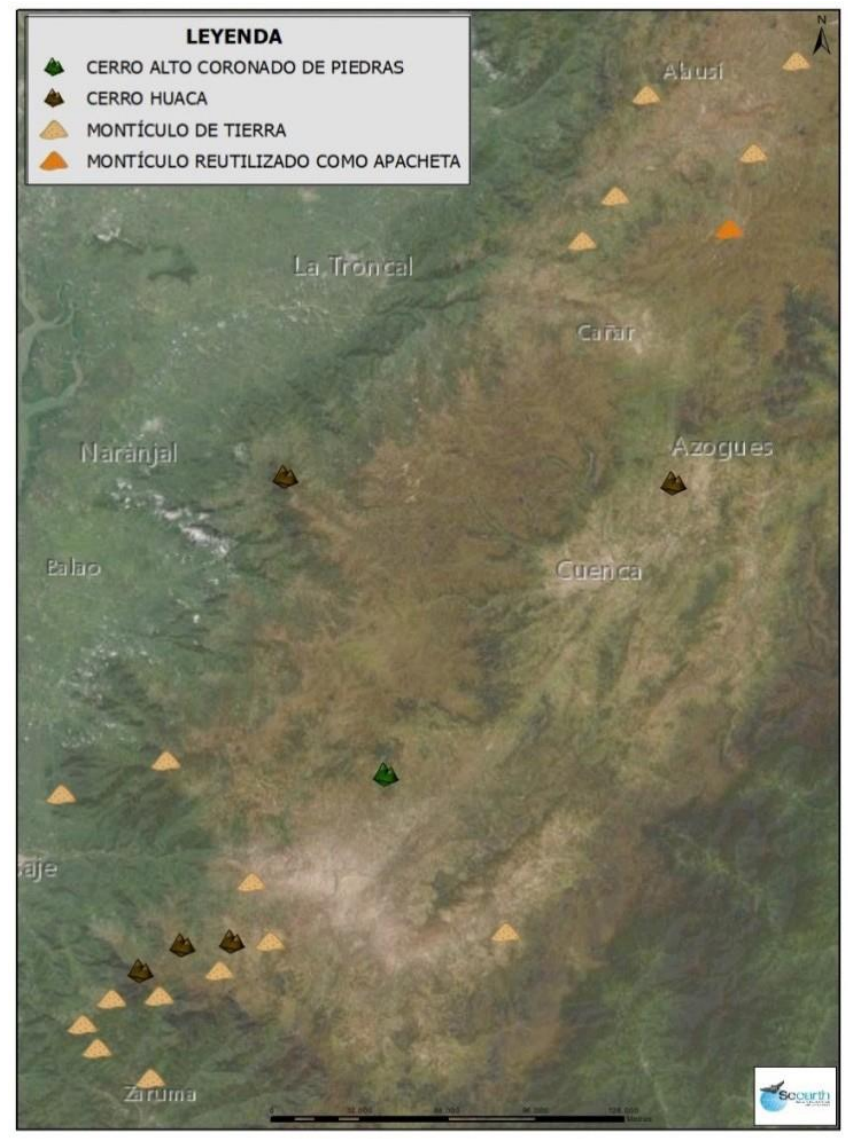

Figura 1: Ubicación de algunos sitios ceremoniales de los antiguos cañaris, conforme a tabla 1

\section{RESULTADOS Y DISCUSIÓN}

La etnohistoria menciona la presencia de huacas, y cerros sagrados como parte de la espiritualidad de los pueblos andinos. En la actualidad, todavía se escuchan en los andes ecuatorianos leyendas como la del urku yaya, identificado como el dueño de los cerros, con necesidades y requerimientos. Howard (1981:25), menciona que los cerros masculinos son poseedores de riquezas de maíz, de granos y tubérculos y las urku mama, son guardianes de los productos de zonas calientes.
Por otra parte, se señala que antes de la conquista inka hubo diferentes géneros de huacas, unas que llamaban pacariscas como creadoras de sus naturalezas, de diferentes formas y nombres según las provincias y que todos las parcialidades pequeñas o grandes tenían su huaca pacarisca (Duviols 1967:20). Arriaga (1968:12) señala que vivían en partes altas y difíciles a causa de su pacarisca y que cada cabeza de Ayllu seleccionaba su pacarina.

Los cañaris en su mitología relacionan a los montes como parte de sus leyendas y consideran al cerro Guasaynan, Guacaynan o Guasano, como la huaca principal que simbolizaba su origen, adonde huyeron del diluvio y otras supersticiones (Cobo 1964; Duviols 1967).

A ciertas huacas, la etnohistoria las designa como cerros señalados, aunque no especifica sus 
nombres, se señala que algunos estaban coronados con piedras. Albornoz (Duviols 1967:32) nombra, para los cañaris anansayas, las huacas con piedra Capatone del Ayllo de Lleuin; Reuissi del Ayllo de Anunoc; Quica del Ayllo de Cauansibies y Saysapa, del Ayllo del mismo nombre. Para los cañares hurinssayas nombra a Puna, cerro alto de piedra.

Otras huacas nombradas por Albornoz y que tienen asimismo piedras son Uisiguiuma del Ayllo de Paycara y el cerro de Mollotoro; esta última la señala como huaca principal de los cañaris y en donde Topa Inga Yupanqui superpuso otras huacas (Duviols 1967).

Observemos que Albornoz (Duviols 1967:32), separa las huacas de los cañares anansayas y la de los cañares hurinssayas. Asimismo, a ciertos cerros los llama huacas principales y se insiste en que cada Ayllu tiene una huaca; sugiriendo un sinfín de huacas cañaris.

Cerros huacas conocidos son también Coxitambo y la Meseta Pachamama. El cerro Coxitambo, fue encontrado lleno de sepulturas y sin construcciones inkas (Bedoya 1978:34); no obstante, según De Gallegos (1992:388), el cerro fue adorado por estos.

González (1969:285) interpreta, en un objeto sacado de los sepulcros, comoel plano de Chordeleg y señala, entre otros elementos, la presencia de dos torrecillas o pirámides truncadas que representan a las colinas de Llaver y Zhaurinzhi. La primera, según el historiador, conservaba hasta el año 1880 los restos de muro de piedra tosca.

Moreno (2007:178) estudia detalladamente al cerro Supay Urcu como una huaca importante de los cañaris e identifica al cerro Capatone como el mismo Supay Urcu.

Por otra parte, Verneau y Rivet (2009:68) indican que la colina de Curitaqui es el cerro de Supay Urcu. Juan de Velasco (1927:35) afirma que en ese cerro los cañaris tenían un templo dedicado al demonio, donde sacrificaban niños antes de sus cosechas, costumbre que permaneció hasta en época de los españoles.
Duviols (1977:39) señala al respecto, que los cronistas llamaban Supay (Cupay) al demonio, pero que este también representaba un espíritu bueno, que cambió a malo cuando la palabra pasó al mundo ideológico de los evangelizadores. Según Duviols (1977), también los cronistas se encargaron de convencer a los indios para que cada una de sus divinidades y el demonio fueran la misma cosa e incluyeran dentro del espíritu general del Zupay, a cada una de sus huacas. Probablemente el cerro Capatone o Supay Urcu fue una huaca cañari, utilizada durante la época inca e influenciada por los conceptos de los conquistadores españoles.

Evidencias materiales localizadas en la sierra centro sur son descritas por Haro (1977:22), quien identifica en el sitio Danas, graderíos y cercados similares a un adoratorio o a una fortaleza cañari. Por otra parte, Collier y Murra (2007:31) hallan seis churos y señalan que, en uno de ellos, el de Llullín, en la plataforma más alta hay una estructura circular de piedra de $2 \mathrm{~m}$ de alto con un cuarto pequeño y rectangular en el lado norte y mencionan que fue hecho por un grupo tardío.

Otra estructura de tierra fue localizada al noreste de Achupallas, el sector lo llaman Chapito Loma, consiste en una plataforma de tierra de $15 \mathrm{~m}$ x 11 $\mathrm{m}$ con una estructura circular de roca de aparejo de tipo rústico de aproximadamente $1.30 \mathrm{~m}$ de alto, como se observa en la figura 2 (Galarza, comunicación personal, 1 de mayo, 2019).

En Ingapirca (Cañar), la edificación llamada El Castillo es interpretada como un monumento inka de carácter místico, erigido sobre una construcción local, en cuyo centro se hallaría una pacarina o huaca sagrada (Alcina 1978:135).

Asimismo, es muy probable que la apacheta Tres Cruces por su ubicación en el punto más alto del Nudo del Azuay, fuera inicialmente una pacarina cañari y que posteriormente haya sido reutilizada como un espacio sagrado por parte de los incas. Se destaca que las apachetas son lugares donde los viajeros dejaban ofrendas y se encuentran en los puntos donde los Andes descienden (Hyslop 1992:201; también véase Hyslop 2016:318). 
Fuente: Fotografía cortesía de Galarza (2019)

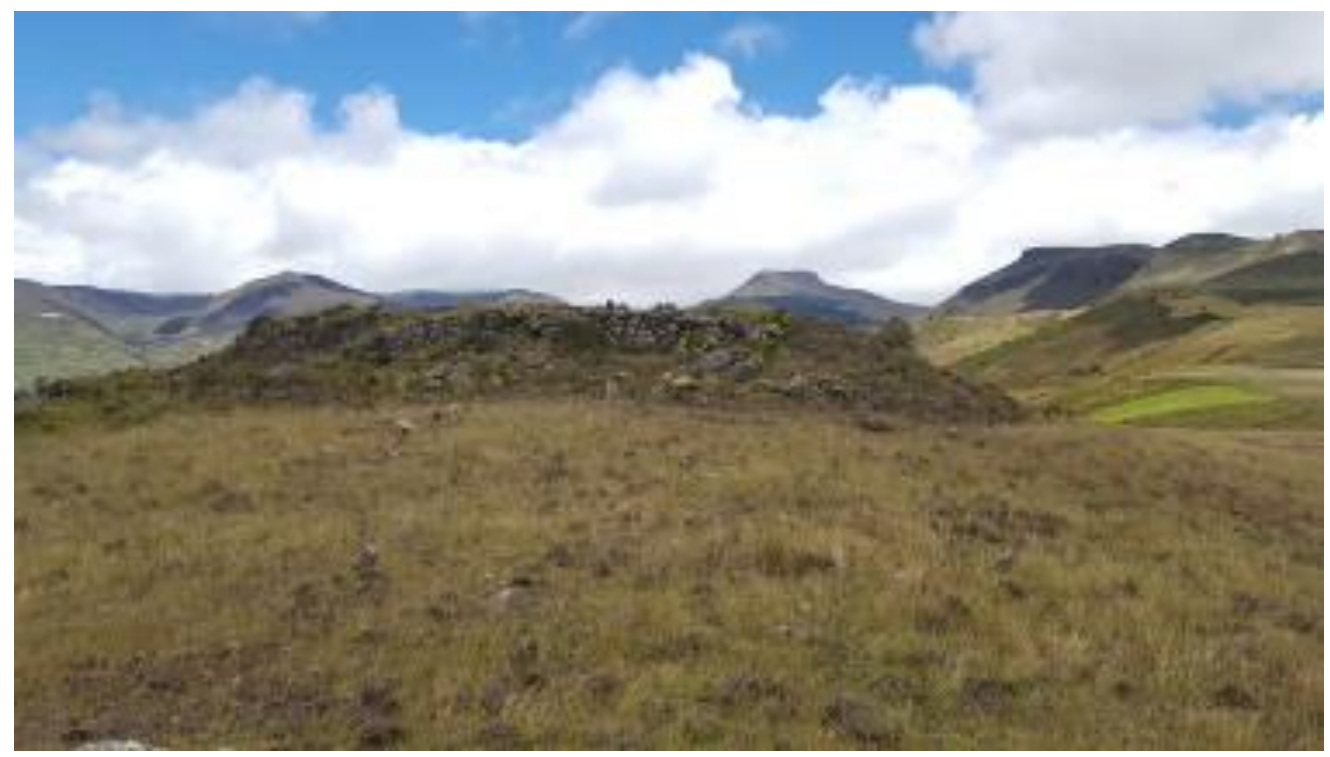

Figura 2: Sitio Chapito Loma, plataforma de tierra en la cúspide del cerro

En el cerro Shungumarca existe una plataforma de tierra que Reinoso (1971:231) describe como montículo truncado con terrazas rodeadas de muros, con un corte diametral de $13.60 \mathrm{~m}$ de largo por $1.54 \mathrm{~m}$ de ancho y $0.80 \mathrm{~m}$ de profundidad; con una altura menor a los $2 \mathrm{~m}$ y construida de piedras andesitas rotas, con sus caras planas expuestas hacia el exterior y las ranuras rellenadas con cuñas de piedra de diversos tamaños; también, señala una estructura rectangular en la cima.

Por su parte, Idrovo (2006:50) reporta la presencia de una estructura circular de $7 \mathrm{~m}$ de diámetro y $1.40 \mathrm{~m}$ de altura en la parte más alta del sector Guabo Alto en el cantón de Santa Isabel; construida con cantos rodados y bloques desbastados en su parte exterior, con ángulos bien formados, unidos con argamasa y relleno de lastre amarillo. El investigador plantea que sirvió de santuario y que está asociada con cerámica formativa.

En el cerro Campana, cuenca alta del Jubones, Galarza (citado en Jadán 2015) encontró piedras en su cúspide. En tanto, en la loma de Shuñin, Marca (citado en Jadán 2015) informa la existencia de dos montículos o altares formados por varias capas de tierra poco compacta de color amarillento. Para el valle del río Cuyes y Saraguro, también se menciona la presencia de cerros con adoratorios (Salazar 2004:67).

En el sector este del sitio Mirador de Mullupungo, Odaira (1998:148) identifica una edificación en forma de terraza y sin escaleras y en la cima una pequeña construcción circular de $4.5 \mathrm{~m}$ de diámetro, hecha con tierra y con un muro de piedras trabajadas y unidas con una argamasa de barro de color negro; le llama la atención el derrumbamiento de la sección norte y considera que la destrucción se realizó para la edificación de nuevas estructuras. Esta información sugiere que esta edificación fue una pacarina cañari y que los incas intentaron destruirla para reedificar el sitio.

En Chillacocha, Verneau y Rivet (2009:109-

111) localizaron tres construcciones en las cimas de los cerros de tamaños y arquitectura similar, pertenecientes a pueblos locales. Los autores detallan las siguientes características: una primera construcción que forma una especie de terraplén de tierra acarreada, casi circular de 8 a 10 m de diámetro, sostenida por un muro de tierras calcinadas y fragmentos de rocas locales cimentadas con tierra. Según los investigadores, la plataforma parece haber presentado en el lado este una escalera de acceso, toscamente construida. 
En el mismo pico de la montaña, hacia el norte, se encuentra otra estructura similar a la anterior, ubicada en una zona abrupta de $7 \mathrm{~m}$ a $8 \mathrm{~m}$ de diámetro y con muros de $1.50 \mathrm{~cm}$ de alto por $0.55 \mathrm{~m}$ de espesor, elaborados igualmente con fragmentos de roca, tierra y una especie de arcilla. El tercer hallazgo se encuentra a unos $150 \mathrm{~m}$ del camino de Guanasag a Yulug, cerca de las abras de roca de Paltacalo y tiene de 7 a $8 \mathrm{~m}$ de circunferencia.

En la cordillera de Pallana (cordillera de Chilla) y al oeste de un área de terrazas del sitio arqueológico Chepel, González (1956:148) señala la presencia de un montículo artificial construido de piedra y tierra, llamado "la mesa" por los propietarios; la describe como una construcción de tres pisos, con un muro de piedra de $1.20 \mathrm{~m}$ de altura que contornea la base del primer piso; en el lado este, una depresión del terreno y en la parte de la estructura distingue varias gradas de $4.5 \mathrm{~m}$ de ancho, que forman una escalinata bordeada por muros laterales, hechos con piedras labradas, como pilones altos a manera de pasamanos y de intervalo en intervalo, unas pocas piedras largas enclavadas que sobresalen de los muros.
En el sitio Yacuviña, Idrovo (citado en Jadán 2015), menciona un conjunto $\mathrm{E}$ o templo preincaico dedicado a una divinidad andina como Apu Catequilla.

Otra de estas plataformas de tierra está localizada en una pequeña cima en el sitio Daucay. Se trata de una estructura circular de $9 \mathrm{~m}$ de diámetro, tiene una altura entre $10 \mathrm{c} 40 \mathrm{~cm}$ y $80 \mathrm{~cm}$ y $80 \mathrm{~cm}$ de ancho. (Galarza et al. 2014:319).

En la cima del sitio Guiñayzhu (cordillera de Chilla) existe una construcción circular en la cúspide del cerro, con el lado norte que limita al declive. Está sostenida por fragmentos de rocas rústicas de diferentes tamaños. La plataforma, que se encuentra en el nivel inferior, tiene $8.5 \mathrm{~m}$ de diámetro y la superficie superior tiene $6.5 \mathrm{~m}$; ambas plataformas tienen $3 \mathrm{~m}$ de alto (figura $3 \mathrm{~B}$ ).

También se observó al pie de la plataforma en la siguiente terraza, estratos de suelo y cerámica de una ocupación local; evidencias que corresponden a una vivienda, probablemente del cacique y su familia.

Fuente: Fotografías tomadas por la autora en 2015

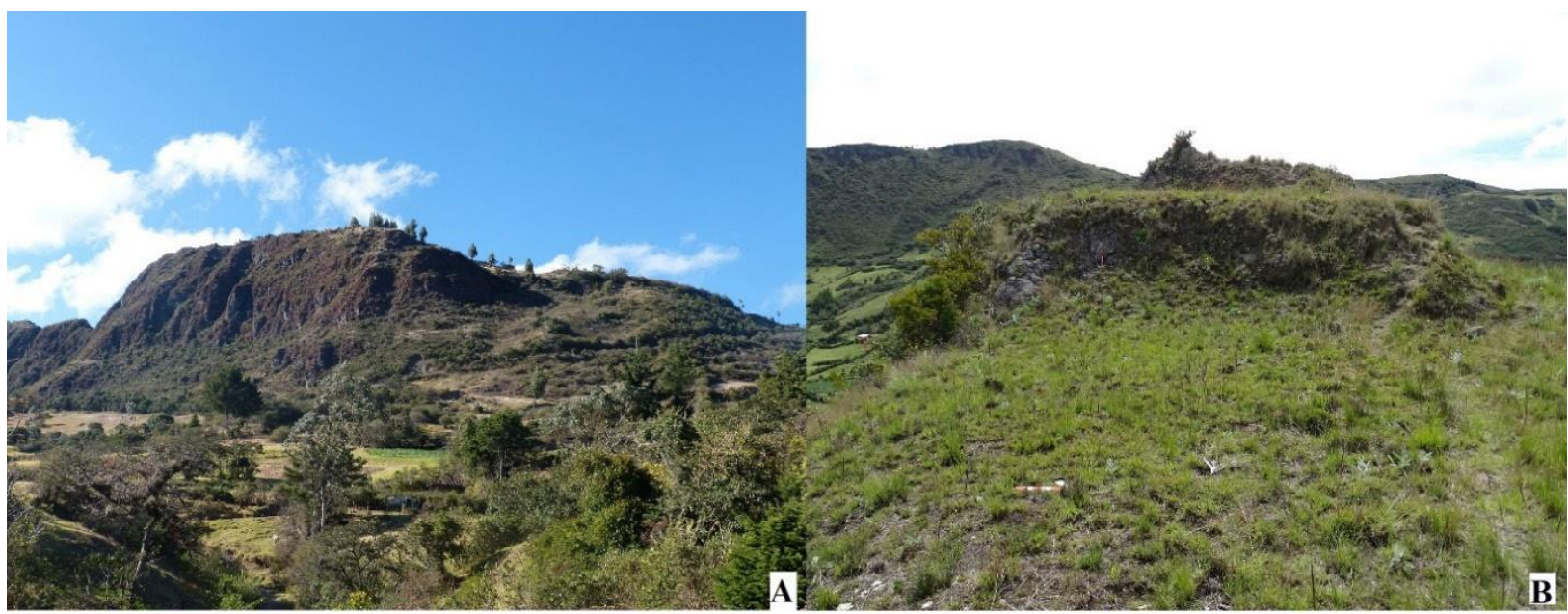

Figura 3: A. Sitio arqueológico Cerro Guiñayzhu. B. Plataforma que corona el mismo sitio 
Sarmiento (1993:97) considera que la religión o ritual, durante el sistema de cacicazgos fue un medio de cohesión social; pero también la religión entregó a los caciques un fuerte poder y control. En relación con eso, también Gaviria (1992:401) y De Salinas (1992:142) señalan que los indios estaban sujetos y sometidos a los señores caciques. Por la cerámica recurrente en la región de la cordillera de Chilla y el piso de ocupación en Guiñayzhu, proponemos que perteneció a un cacicazgo cañari.

Existen otros cerros en la cordillera de Chilla, respetados en la actualidad por los pobladores locales, donde se ha localizado cerámica cañari y evidencias de arquitectura inka, como Gallo Cantana, Pirámide Truncada (figura 4), ambos son de corte piramidal. También hay sitios como Paltacalo, cerro Repén, Rodeo y la cordillera de Portete; en esta última se ha colocado una urna de la Virgen de Chilla.

También, ciertos afloramientos rocosos fueron venerados por los indígenas, así, hasta el año 1815 disputaban e inventaban excusas con el dueño de la hacienda Ganacay, para que no se retirara una roca en un antiguo camino (Checa 2014:40). A este tipo de huaca, Albornoz las nombra huacas Ormaychic, y se encuentran debajo de peñas o cerros que amenazan caídas (Duvoils 1967:19).
La información sugiere la continuidad de la devoción de los señoríos cañaris. Al presente, las comunidades locales las veneran y también realizan peregrinaciones hacia estos cerros y peñascos. Rostworowski (2003:97) señala que la práctica de peregrinaciones bajo la advocación de divinidades católicas fue la única manera de que los naturales conservaran sus creencias andinas. En la tabla 1 se presentan los nombres de los lugares con construcciones de tierra o cerros coronados con piedras.

En el caso de Puñay, cerro situado en la frontera norte del territorio cañari, posee un contexto ritual interesante: tres plataformas de tierra con diferentes funciones. Una primera plataforma se encuentra en el espacio central de toda la cumbre, tiene un área $1445 \mathrm{~m}^{2}$ y una altura $3262 \mathrm{~m}$. s. n. $\mathrm{m}$.; guarda la mayor cantidad de restos culturales del sitio, lo que sugiere una mayor dinámica en ese espacio (Jadán 2017:29).

Fuente: Fotografías tomadas por la autora en 2008

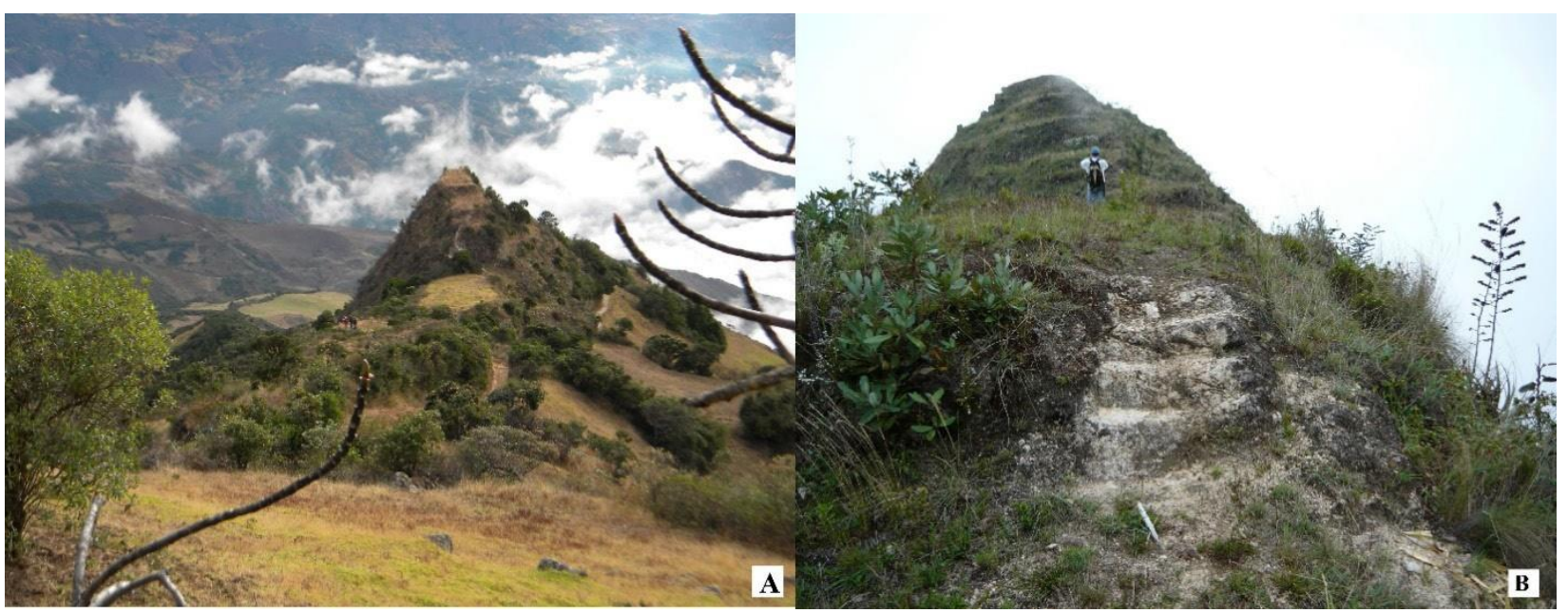

Figura 4: Cerros huacas ubicados en la cordillera de Chilla. A. Gallo Cantana. B. Pirámide Truncada 
Tabla 1: Resumen de sitios con montículos de tierra y cerros coronados con piedra

\begin{tabular}{|c|c|c|}
\hline Sitio arqueológico & Características & Fuente \\
\hline Churo Llullín & Montículo y estructura circular de roca $2 \mathrm{~m}$ de altura & Collier \& Murra 2007 \\
\hline Danas & Montículo de tierra & Haro L. (1977) \\
\hline Chapito Loma & Montículo de tierra con estructura de roca, $1.30 \mathrm{~m}$ altura y tamaño & Comunicación personal Galarza B. \\
\hline Cerro Puñay & Montículo de tierra y roca. Diámetro 28.48 & Jadán 2010 \\
\hline Tres Cruces & Montículo reutilizado como apacheta & Hyslop 1992 \\
\hline Shungumarca, & Montículo de tierra y muro con rocas. $2 \mathrm{~m}$ altura. Diámetro $13.6 \mathrm{~m}$ & Reinoso 1971 \\
\hline Coxitambo & Cerro de peña viva & Gallegos (1992) \\
\hline Mollotoro & Cerro muy grande (reutilizada por Topa Inca Yupanqui) & Duviols (1967) \\
\hline Mirador de Mullupu & Montículo de tierra y muro de roca. Diámetro $4.5 \mathrm{~m}$ & Odaira 1998 \\
\hline Campana & Cerro alto coronado de piedras & Galarza V. 2011 \\
\hline El Guabo Alto & Estructura con cantos de piedra, $1.3 \mathrm{~m}$ altura. Diámetro $8 \mathrm{~m}$ & Idrovo 2006 \\
\hline Ganacay & Muro de roca circular. Diámetro $13 \mathrm{~m}$ & Casa de la Cultura 2010 \\
\hline Shuñin & Dos montículos de tierra & Marca 2011 \\
\hline Paltacalo & Montículo de tierra y muro de roca. $1.5 \mathrm{~m}$ altura. Diámetro $8 \mathrm{~m}$ & Jadán 2009 \\
\hline Gallo Cantana & Cerro piramidal & Jadán 2015 \\
\hline Pirámide Trucada & Cerro piramidal & Jadán 2015 \\
\hline Cordillera Portete & Peñasco & Jadán 2015 \\
\hline Guiñayzhu & Montículo de tierra y roca. Diámetro $8.5 \mathrm{~m}$ y $6.5 \mathrm{~m}$ & Jadán 2015 \\
\hline Chilla Cocha 1 & Montículo de tierra y muro de roca. Diámetro $10 \mathrm{~m}$ & Verneau y Rivet 2009 \\
\hline Daucay & Montículo de tierra y muro de roca. $0.80 \mathrm{~m}$ altura. Diámetro $9 \mathrm{~m}$ & Galarza B. 2014 \\
\hline Yacuviñay & Cima del Cerro & Idrovo 2000 \\
\hline Chilla Cocha 2 & Montículo de tierra y muro de roca. $1.5 \mathrm{~m}$ altura. Diámetro $8 \mathrm{~m}$ & Verneau y Rivet 2009 \\
\hline Chepel & Montículo de tierra y muro de roca. $1.2 \mathrm{~m}$ altura. Diámetro $12 \mathrm{~m}$ & C. Gonzáles 1956 \\
\hline Capatone & Cerro coronado de piedras, junto al pueblo de Xuque & Albornoz 1967 \\
\hline Curitaqui-Supayurc & Cerro coronado de piedras & Moreno (2007); Verneau \& Rivet 2009 \\
\hline Guasaynan & Cerro alto representa mitología de origen & Duviols (1967) \\
\hline Reuissi & Cerro grande coronado de piedras & Duviols (1967) \\
\hline Quica & Cerro grande coronado de piedras & Duviols (1967) \\
\hline Uisigui uma & Cerro grande coronado de piedras & Duviols (1967) \\
\hline Saysapa & Cerro & Duviols (1967) \\
\hline Abgna & Cerro muy alto y suntuoso & Gallegos (1992) \\
\hline
\end{tabular}

Fuente: Jadán 2015

Una segunda plataforma o montículo ceremonial se encuentra al sur, está moldeada en forma circular y está situada en una de las coronas del cerro, con un área de $528.1 \mathrm{~m}^{2}$, un diámetro de $29 \mathrm{~m}$ y a una altura de $3265 \mathrm{~m} \mathrm{~s}$. n. m. (figura 5).

Fuente: Fotografías del Proyecto de Investigación en Cerro Puñay, año 2010

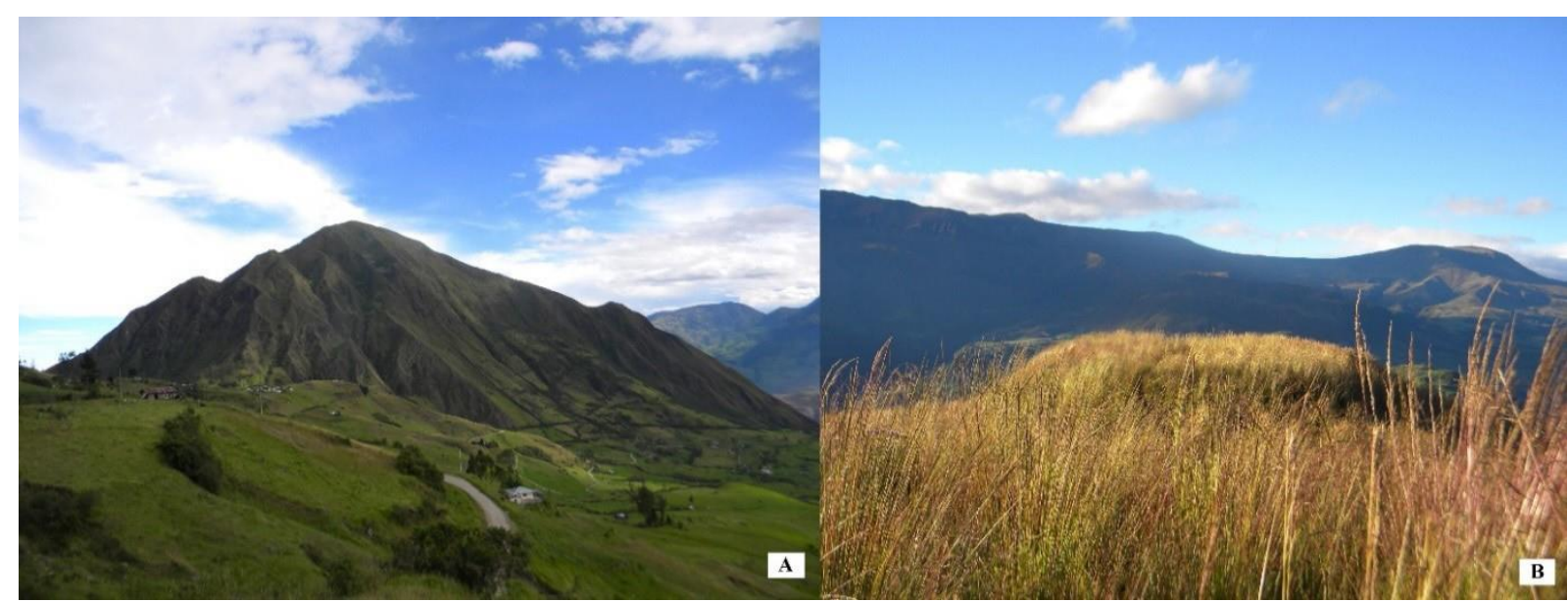

Figura 5: A. Sitio arqueológico Cerro Puñay. B. Estructura Circular en el mismo cerro, vista desde la plataforma central 
Una tercera y última plataforma con $186.3 \mathrm{~m}^{2}$, situada al oeste y a una altura de $3240 \mathrm{~m} \mathrm{~s}$. n.

m. permite observar la costa y el mar. Además, dentro del mismo sitio y por los alrededores de los caminos de acceso, hay una serie de terrazas de función agrícola y probablemente ceremonial.

La cerámica encontrada en la cima central corresponde a una vajilla burda, gruesa, alisada, con colores de pasta variable y con bordes del tipo doblado, similar a otros sitios cañari. En cambio, los depósitos profundos arrojaron cerámica Narrío del tipo pintura roja sobre ante y cerámica Cerro Narrío con decoraciones antropomorfas (Jadán 2017:29).

Esta información sugiere que desde el Formativo Tardío y luego en el Periodo de Integración los grupos locales subían al cerro para venerarlo, como lo demuestra la existencia de caminos de tierra que lo atraviesan, además del camino de piedra labrada de origen inka en plena cuchillla (figuras 6 y 7).

Fuente: Fotografías del Proyecto de Investigación en Cerro Puñay, año 2010

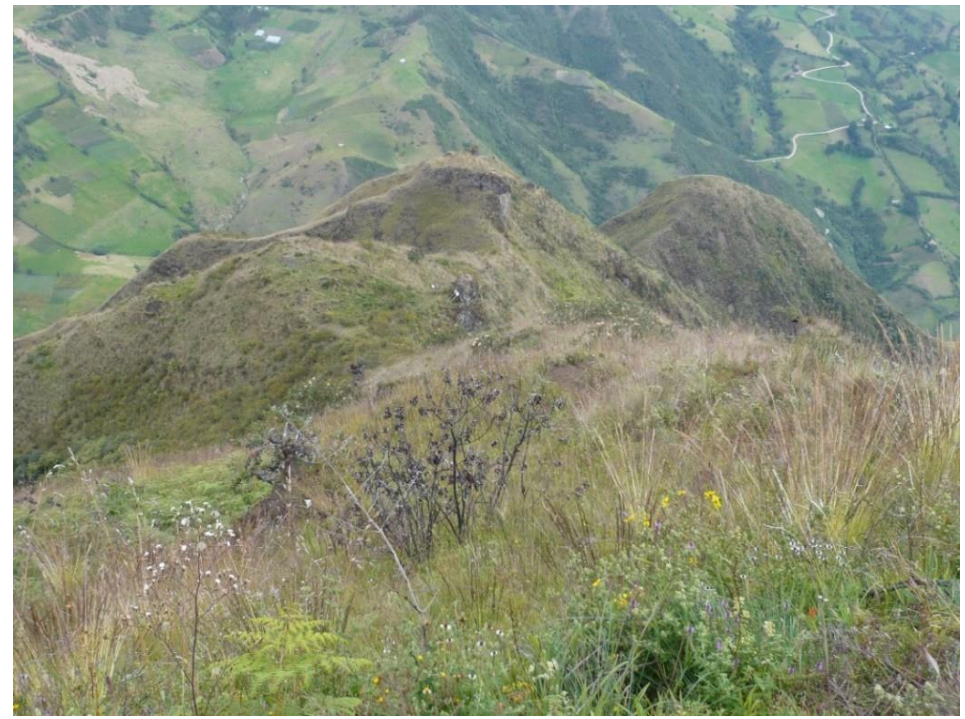

Figura 6: Camino ceremonial preinca de acceso desde el sur hacia Puñay

Fuente: Fotografías del Proyecto de Investigación en Cerro Puñay, año 2010

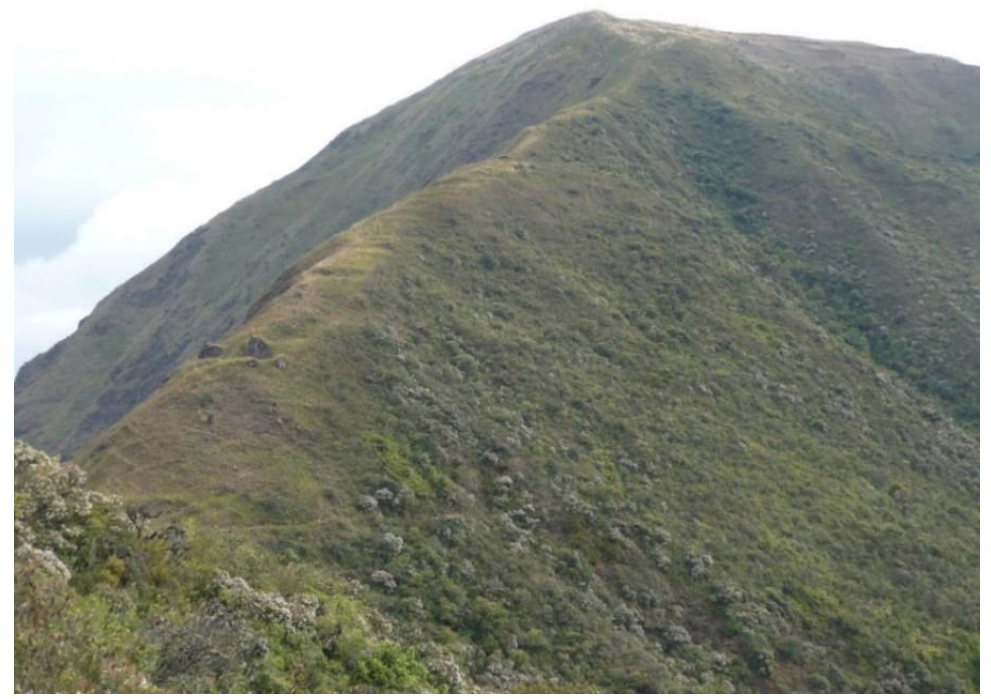

Figura 7: Camino ceremonial de acceso desde el norte hacia Puñay, nótese los mojones líticos 
Desde el sur, seguramente a partir de las poblaciones de Santa Rosa, Llagos, Joyaczhi; y desde el lado norte, los senderos unían las poblaciones cañaris de Chico Nantza, Cochabamba, Pacchala; también, otras poblaciones del lado este, como Compud, Pasaloma, Pinancay y Capsol llegaban probablemente hasta Puñay; es decir, había más de un sendero utilizado por los pueblos aborígenes que venían de todos lados (Jadán, Carretero \& Galarza 2018:62).

No obstante, el sitio tiene otras transformaciones respecto a su arquitectura ejecutada durante la época inka. Los sectores oeste y este de la cima central están afianzados con suelos transportados o arqueo sedimentos que consolidan las partes más bajas. El sector noroeste tiene, asimismo, arqueo sedimentos con roca y suelo, un conglomerado que da la apariencia de un aparejo ensamblado para apuntalar un sector probablemente importante del sitio (Jadán 2017).

Por otra parte, las reconstrucciones de parte de los inkas muestran una cima central modificada a manera de plataforma alargada que se empata mediante una rampa de acceso y coincide con un graderío que conecta con el camino que se dirige por la cuchilla del cerro hacia el norte. Este camino fue reconstruido por el incario con rocas labradas y enlaza a Puñay con sitios arqueológicos asociados a la sociedad cañari e inka.

Moore (1996:789) define a estos espacios como áreas sin techo, no domésticas, reconocibles en el ambiente de los edificios. Señala que los elementos comunicativos del ritual, las propiedades espaciales de las plazas y la proxemia de la comunicación humana pueden proporcionar nuevas ideas sobre el entorno prehistórico. La distancia desde la plataforma de Puñay hacia la huaca es entre 100 m a $105 \mathrm{~m}$, una distancia adecuada como para visualizar un ritual y considerando además que la pacarina está en una posición más elevada que la plataforma (Figura 5 b).

Por otra parte, si relacionamos el tamaño de la plataforma y consideramos a una persona por cada metro cuadrado, tenemos un total de 1445 individuos sobre la plataforma o plaza. Jacob (1967: 39) proyecta una cifra de densidad de entre $0.60 \mathrm{~m}^{2}$ a $0.78 \mathrm{~m}^{2}$ para cada persona sentada; en este caso se ha propuesto un espacio ligeramente mayor, es decir: $1 \mathrm{~m}^{2}$ por persona.

La ocupación considerable de este espacio central es corroborada por la mayor cantidad de cerámica cañari encontrada en el mismo. Además, Arriaga (1968:21) manifiesta que no todos los indios veían la huaca principal, ni entraban al sitio donde la huaca estaba, sino solo los hechiceros, que hablaban con ella y le llevaban las ofrendas; aquello explicaría de alguna manera la mayor cantidad de restos culturales en la plataforma central, más no en la huaca (plataforma sur), como tampoco en la plataforma oeste que guardaba otra función. Esta última plataforma permite apreciar los territorios costeños y el mar.

Albornoz (Duviols 1967:13) señala que las huacas pacariscas redificadas fueron los cerros de nieve y volcanes con vistas al mar y los ríos. Quizás esta fue la razón por la que Puñay fue reedificada por los inkas. También, la serie de terrazas presentes en el sitio y camino de acceso, dan cuenta de sembríos dedicados probablemente a la huaca; Albornoz (Duviols 1967) y Arriaga (1968:18) refieren que las huacas tenían servicios, chácaras, ganados, vestidos y sus particulares sacrificios.

Asimismo, Albornoz (Duviols 1967:20) explica que las huacas en las poblaciones locales constituyeron una superstición que nunca desapareció, a pesar de la insistencia de los inkas en apartarla y que ninguna parcialidad o naturales, por pequeños o grandes que fuesen, dejaron de tener una huaca, ya que muchas se reedificaron y otras fueron respetadas para su veneración.

\section{CONCLUSIONES}

Se ha observado, tanto en los documentos etnohistóricos como en los arqueológicos, que un rasgo recurrente en sitios cañari es la plataforma circular de tierra construida en la cima de la colina. Dicha plataforma a veces conserva un muro de rocas rústicas cortadas en su lado externo e intercalado con pequeños cuños para calzar la 
edificación; otras plataformas guardan estructuras circulares o rectangulares sobre su cumbre. Se ha planteado que esta evidencia está relacionada con las pacariscas citadas en la etnohistoria, como huacas que encarnaban el origen de los pueblos locales en épocas pre-inka y fueron lugares de ritualismo y peregrinaje.

En Guiñayzhu, si bien gran parte del sitio fue reconstruido durante la época inka con colcas, la plataforma de tierra de origen local que se encontraba en la parte alta del cerro se mantuvo durante el incario y todavía es respetada por las poblaciones locales. En relación con el Cerro Puñay, el sitio conservó elementos relacionados con actividades de veneración y peregrinaje. Los caminos aborígenes que lo atraviesan y la cerámica local encontrada en el mismo sugieren un flujo y movimiento de personas entrando y saliendo del cerro desde la época preinca. Las investigaciones apuntan que el Cerro Puñay fue reedificado por el imperio inka con fines ceremoniales, pero Guiñayzhu fue reconstruido como sitio de almacenaje y conservó la plataforma ceremonial local.

Este estudio de tipo exploratorio de ninguna manera es concluyente, sin embargo, conduciría a plantear que los llamados cerros señalados fueron los mismos donde en sus cumbres, se colocaban piedras o plataformas de tierra; aparentemente relacionadas con la religiosidad de los cerros y constituyeron probablemente las pacariscas de los señoríos cañaris. Este artículo es apenas el inicio de una investigación, es necesario observar la recurrencia de estas evidencias en nuevos sitios e investigar otros indicadores arqueológicos respecto a la ritualidad.

\section{DECLARACIÓN DE CONFLICTOS DE INTERESES:}

Los autores declaran no tener conflictos de interés.

\section{REFERENCIAS BIBLIOGRÁFICAS}

Alcina, J. (1978). Ingapirca: arquitectura y áreas de asentamiento. Revista Española de Antropología Americana, 8, 127-146.

Arias, P. (1992). Pacaibamba o Leoquina. En

P. Ponce. (Ed.), Relaciones Histórico Geográficas de la Audiencia de Quito Siglo XVI - XIX (pp. 390-394). Quito, Ecuador: Abya-Yala.

Arriaga, P. (1968). Extirpación de la idolatría del Pirú. Crónicas Peruanas de Interés Indígena. 209, 191-277.

Bedoya, A. (1978). La Arqueología en la Región Interandina del Ecuador. Quito, Ecuador: Casa de la Cultura Ecuatoriana.

Cobo, B. (1964). Historia del Nuevo Mundo. Madrid: Atlas.

Collier, D. \& J. Murra. (2007). Reconocimiento $y$ excavaciones en el Austro ecuatoriano. Cuenca, Azuay: Casa de la Cultura Ecuatoriana.

Checa, S. (2014). Yacuviña. Loja, Ecuador: Instituto Nacional de Patrimonio Cultural.

Cieza de León, P. (2005). Crónica del Perú El Señorío De Los Inkas. Caracas, Venezuela: Fundación Biblioteca Ayacucho.

De Gallegos, G. (1992). San Francisco Pueleusi del Azogue. En P. Ponce. (Ed.), Relaciones Histórico Geográficas de la Audiencia de Quito Siglo XVI - XIX (pp. 385-390). Quito, Ecuador: Abya-Yala.

De Gaviria, M. (1992). Santo Domingo de Chunchi. En P. Ponce. (Ed.), Relaciones Histórico Geográficas de la Audiencia de Quito Siglo $X V I-X I X$ (pp. 400-403). Quito, Ecuador: Abya-Yala. 
De Salinas, J. (1992). Relación y descripción de la ciudad de Loxa. En P. Ponce. (Ed.), Relaciones Histórico Geográficas de la Audiencia de Quito Siglo XVI - XIX (pp. 122-142). Quito, Ecuador: Abya-Yala.

Duviols, P. (1967). Un inédit de Cristóbal de Albornoz: La instrucción para descubrir todas las guacas del Pirú y sus camayos y haziendas. Journal de la société des américanistes, 56(1), 7-39.

Duviols, P. (1977). La destrucción de las Religiones Andinas (Conquista y Colonia). México: Universidad Nacional Autónoma de México.

Galarza, B., Almeida, N. \& Guzmán, S. (2014). Daucay Conjunto Arqueológico monumental tardío en la cordillera Homónima, Provincia de El Oro. En Estudios Multidisciplinarios en Cinco Espacios Prehispánicos Tardíos del Ecuador (pp. 312-326). Cuenca, Ecuador: Serie Estudios.

Garcilaso de la Vega, I. (1609). Comentarios Reales De Los Inkas. Recuperado de http:// museogarcilaso.pe/mediaelement/pdf/3ComentariosReales.pdf

González, F. (1878). Estudio histórico sobre los Cañaris, antiguos habitantes de la provincia del Azuay en la República del Ecuador. Quito, Ecuador: J. Guzmán Almeida.

González, F. (1969). Historia General De La República Del Ecuador. Quito, Ecuador: Casa de la Cultura Ecuatoriana.

González, C. (1956). Estudios Arqueológicos en el Cantón Zaruma. Boletín órgano de las secciones científicas de la Casa de la Cultura Ecuatoriana, 9(78), 138-157.

Haro, L. (1977). Puruhá Nación Guerrera. Quito: Editora Nacional.

Hyslop, J. (1992). Qhapaqñan El Sistema Vial Inkaico. En E. Mujica (ed.). Lima: Instituto Andino de Estudios Arqueológicos.

Hyslop, J. (2016). Asentamientos Planificados Inka. Lima: Petróleos del Perú

Howard, R. (1981). Dioses y Diablos Tradición oral de Cañar Ecuador. Paris, France:
Amerindia revue $\mathrm{d}$ ethnolinguistique amerindienne.

Idrovo, J. (2006). Informe de Prospección Arqueológica del Cantón Isabel. Santa Isabel, Ecuador: Ilustre Municipio del Cantón Santa Isabel.

Jacobs, H. (1967). To count a crowd. Columbia Journalism Review, 6, 36-40.

Jadán, M. (2015). La Presencia de la Sociedad Cañari en la cordillera de Chilla, al Sur occidente de los Andes del Ecuador: Una perspectiva desde el sitio Guiñayzhu (tesis de maestría). Escuela Superior Politécnica del Litoral, Guayaquil, Ecuador.

Jadán, M. (2017). La arquitectura de tierra y las ocupaciones humanas en el sitio arqueológico Cerro Puñay, cantón Chunchi, provincia de Chimborazo, Ecuador. Arqueología Iberoamericana, 34, 21-31.

Jadán, M. (2018). Apropiación inka en la cordillera de Chilla, suroeste de los Andes del Ecuador: el caso del sitio Guiñayzhu. Arqueología Iberoamericana, 37, 13-22.

Jadán, M., Carretero, P. \& Galarza, B. (2018). Caminos aborígenes conectados al Qhapaq Ñan, cuenca del río Chanchán, provincia de Chimborazo, Ecuador. Arqueología Iberoamericana, 40, 54-64.

Moore, J. (1996). The Archaeology of Plazas and the Proxemics of Ritual: Three Andean Traditions. American Anthropologist Journal Article New Series, 98(4), 789-802.

Moreno, S. (2007). Ofrenda Sacrificial en el Guagualzuma. En F. García. (Ed.), Congreso Ecuatoriano de Antropología y Arqueología. Balance de la última década: Aportes, Retos y nuevos temas (pp. 176-200). Quito, Ecuador: Abya-Yala, Banco Mundial del Ecuador.

Odaira, S. (1998). El Mirador de Mullupungo: Un aspecto del Control Inka en la Costa Sur del Ecuador. Tawantinsuyu, 5, 145-152.

Reinoso, G. (1971). Vestigios arqueológicos 
en la región occidental del Nudo del Azuay. Revista de Antropología sección de antropología del Núcleo del Azuay de la Casa de la Cultura Ecuatoriana, (1), 227248.

Rostworowski, M. (2003). Peregrinaciones y procesiones rituales en los Andes. Journal de la société des américanistes, 89(2), 97123.

Salazar,E. (2004). Cuenca y su región: En busca del tiempo perdido. En E. Salazar, D. Jaramillo, J. Martínez, A. Abada \& F. Aguilar. (Eds.), Cuenca Santa Ana de las Aguas (pp. 18-85). Quito, Ecuador: Libri Mundi.

Sarmiento, G. (1993). Tribus y cacicazgos arqueológicos: Una discusión acerca del origen de la estratificación social. Boletín de Antropología Americana, 27, 95-108.

Tarragó, M. \& V. Núñez. (1972). Un Diseño de Investigación Arqueológica sobre el valle Calchaquí: Fase Exploratoria. Estudios de Arqueología, 1, 62-65.

Velasco de, J. (1927). Historia del Reino de Quito en la América Meridional. Quito, Ecuador: Casa de la Cultura Ecuatoriana.

Verneau, R. \& P. Rivet. (2009). Etnografía Antigua del Ecuador. En C. Ramírez. (Ed.), Tres Descripciones De Cuenca y Su Región (pp. 57-111). Cuenca, Ecuador: Casa de la Cultura Ecuatoriana Núcleo del Azuay. 